\title{
Characteristics of powerful learning environments in VET transition program for at-risk students: qualitative insights from teachers and support specialists implementing the program
}

\author{
Liana Roos ${ }^{*}$ (D), Karmen Trasberg, Kristi Kõiv and Egle Säre
}

\section{*Correspondence:}

liana.roos@ut.ee

Institute of Education,

University of Tartu, Salme 1a,

50103 Tartu, Estonia

\begin{abstract}
At-risk students like those with special educational needs, learning difficulties, or pupils at risk of exclusion frequently struggle in transition from basic to secondary vocational education and training, often due to poor personal, learning and social skills. Therefore, several countries implement transition programs like the choice of profession training (COPT) in Estonia to support youngsters'readiness to continue their studies. This study aimed to identify how the characteristics of powerful learning environments in vocational education (PoLEVE) appear in COPT in VET teachers and support specialists' experiences. The deductive thematic analysis of 16 semistructured interviews illuminated the development of learning-, life-, cooperation- and self-determinations skills through adaptive teaching and learning support in a safe and positive learning community. Nevertheless, the results also call for empowering at-risk students to cope independently, supporting their construction of vocational knowledge through reflective dialogue and intellectually challenging problem-solving.
\end{abstract}

Keywords: Transition program, At-risk students, Powerful learning environments, Vocational education and training

\section{Introduction}

Across Europe various transition programs are implemented to increase the inclusion of at-risk students, to prevent learners from dropping out of vocational schools, and to support young people who have left the education system, in the transition to training or labor market (c.f., Fix et al. 2019; Gonzalez-Faraco et al. 2019; Peinemann 2019; Schmid 2020; Walther 2006). The transitions are particularly difficult for people coming from disadvantaged backgrounds (Eurostat 2020). The vast majority of young people struggle with the transition from compulsory basic education to the next educational level (Jäppinen 2012; Kallip and Heidmets 2017). In Estonia-the context of the current study, almost a quarter of the students enrolling in VET drop out on their first year of studies

(c) The Author(s), 2021. Open Access This article is licensed under a Creative Commons Attribution 4.0 International License, which permits use, sharing, adaptation, distribution and reproduction in any medium or format, as long as you give appropriate credit to the original author(s) and the source, provide a link to the Creative Commons licence, and indicate if changes were made. The images or other third party material in this article are included in the article's Creative Commons licence, unless indicated otherwise in a credit line to the material. If material is not included in the article's Creative Commons licence and your intended use is not permitted by statutory regulation or exceeds the permitted use, you will need to obtain permission directly from the copyright holder. To view a copy of this licence, visit http:// creativecommons.org/licenses/by/4.0/. 
(Musset et al. 2019), and only one out of ten of them completes their vocational studies later on (Espenberg et al. 2012) Therefore, successful educational transitions are vital.

Risk factors leading to an unsuccessful transition are complex and intertwined, multifaceted student-, family-, and school-related aspects are presented in the literature. For example, students' gender (Ahola and Kivelä 2007; Jørgensen 2015), special educational needs (Kalalahti et al. 2020), learning difficulties, low self-esteem (Fix et al. 2019), health, their poor engagement, performance, aspirations (Jäppinen 2012), and lack of learning and social skills (Beilmann and Espenberg 2016; Peinemann 2019) contribute to the diverse spectrum of student-related risk factors in transition to VET. There is also evidence that often, students have not figured out their preferred study field (Ahola and Kivelä 2007; Beilmann and Espenberg 2016) and have taken a vocational pathway due to pressure to study from their parents (Beilmann and Espenberg 2016) or have overly high and unrealistic career ambitions (Kalalahti et al. 2020).

In addition to individual characteristics and personal dispositions, students' social environment, such as their family context, peers and networks, and school and classroom climate, are important (Jäppinen 2012). At-risk students' families lower socioeconomic status (Beilmann and Espenberg 2016), dysfunctional family life (Ahola and Kivelä 2007), conflicts with parents, or becoming a parent (Beilmann and Espenberg 2016) can hamper successful transitions. School-related risk factors are a hostile climate at school, e.g., bullying and problematic relationships with teachers and peers (Ahola and Kivelä 2007; Beilmann and Espenberg 2016). Often multiple risk factors are intertwined, making it challenging to reduce those risks and support a successful transition (Munns and McFadden 2000; Peinemann 2019).

As the sociocultural environment of at-risk students often accepts dropout, schools become central in supporting students' efforts to take second chances in education (Munns and McFadden, 2000). Therefore, transition programs are offered with the aim to include at-risk students and to prevent dropout (c.f., Fix et al. 2019; Gonzalez-Faraco et al. 2019; Peinemann 2019; Schmid 2020; Walther 2006). There are structural and cultural differences in transition systems (Walther 2006). The programs can be individually adapted, short-track, prolonged or preparatory (Schmid 2020). Preparatory VET programs offer studies in general subjects and guided opportunities to explore different specialties (Peinemann 2019; Schmid 2020), flexibility and space for choice (Walther 2006). The development of students' social skills and creating positive learning experiences are also significant (Fix et al. 2019). Previous research has emphasized the need for dialogical and constructive multi-professional cooperation between different stakeholders in and outside the school: functional networks are regarded as essential for responding to students' diverse needs and creating a supportive climate for promoting their socioemotional and academic growth (Botha and Kourkoutas 2016; Jäppinen 2012).

In recent years, in Estonia, a similar preparatory transition program to VET was established, namely the choice of profession training (CoPT), a "formal study in preparation for vocational training under which the learning outcomes of the second qualification level and readiness for continuing studies and entering the labor market are achieved" (Standard of Vocational Education 2013). In 2016-2018 CoPT was piloted in two Estonian vocational schools, and since 2019 , the program was adopted permanently by the Estonian Ministry of Education and Research, authorizing that all vocational schools can 
provide CoPT as a formal educational program. The recent developments have heightened the need for providing research-based data on Estonian experiences in implementing the transition program.

As students' engagement and career choices are affected by various social environments, including teaching and the organization of schooling (Niittylahti et al. 2019), this study embraces the theoretical model of powerful learning environments in vocational education (PoLEVE) developed by Placklé et al. $(2014,2018,2020)$. The model places the learner at the center of learning. Challenging and authentic learning tasks, possibilities for developing learners' key competencies, and adaptive support for learning are carried out in a positive and safe learning environment (Placklé et al. 2014, 2018, 2020). Because teachers play a crucial role in creating a supportive learning environment (Königs et al. 2005; Placklé et al. 2018), the study aimed to identify the characteristics of the PoLEVE model in CoPT in VET teachers and support specialists' experiences implementing it. We hope that offering insights into teachers' experiences implementing the transition program through the characteristics of the research-based model of powerful learning environments contributes to a better understanding of what is needed for a successful transition program.

The following chapters first give an overview of the PoLEVE model as a theoretical framework of the study, next the context of CoPT in Estonia is described. The subsequent section outlines the research methodology, followed by the presentation of the research results and discussion. Finally, we draw the conclusion, and give suggestions for further research.

\section{Powerful learning environments in vocational education}

Several authors (e.g., Biemans et al. 2013; de Bruijn and Leeman 2011; Placklé et al. 2014, 2018,2020 ) have drawn on the characteristics of powerful learning environments in their studies on vocational education. Although they partly focused on different aspects of such environments, they agreed on the key characteristics (Königs et al. 2005) and found reflective, authentic, and constructive learning and teaching to be the most important elements (de Bruijn and Leeman 2011; Biemans et al. 2013).

Placklé et al. $(2014,2018,2020)$ proposed a research-based model of the powerful learning environment in vocational education (PoLEVE), placing the student at the center of various tightly integrated and co-dependent components that together support learning and teaching. These characteristics are: (1) challenging and authentic learning tasks; (2) possibilities for the development of learners' key competencies (3) adaptive support for learning; and (4) a positive and safe learning community (see Fig. 1).

Placklé et al. $(2014,2018,2020)$ highlighted authentic and challenging learning tasks as a characteristic of PoLEVE. A learning environment is considered powerful if learning occurs in an authentic context (Könings et al. 2005). Although authenticity in education may vary, the emphasis is on practical learning because it enables an integrated acquisition of vocational skills, key competencies, and professional knowledge (Jossberger et al. 2010). On the other hand, authentic learning "not only involves the application of instrumental skills, but also more general competencies such as arranging, planning, and organization" (de Bruijn and Leeman 2011, p. 697). Besides creating learning situations 


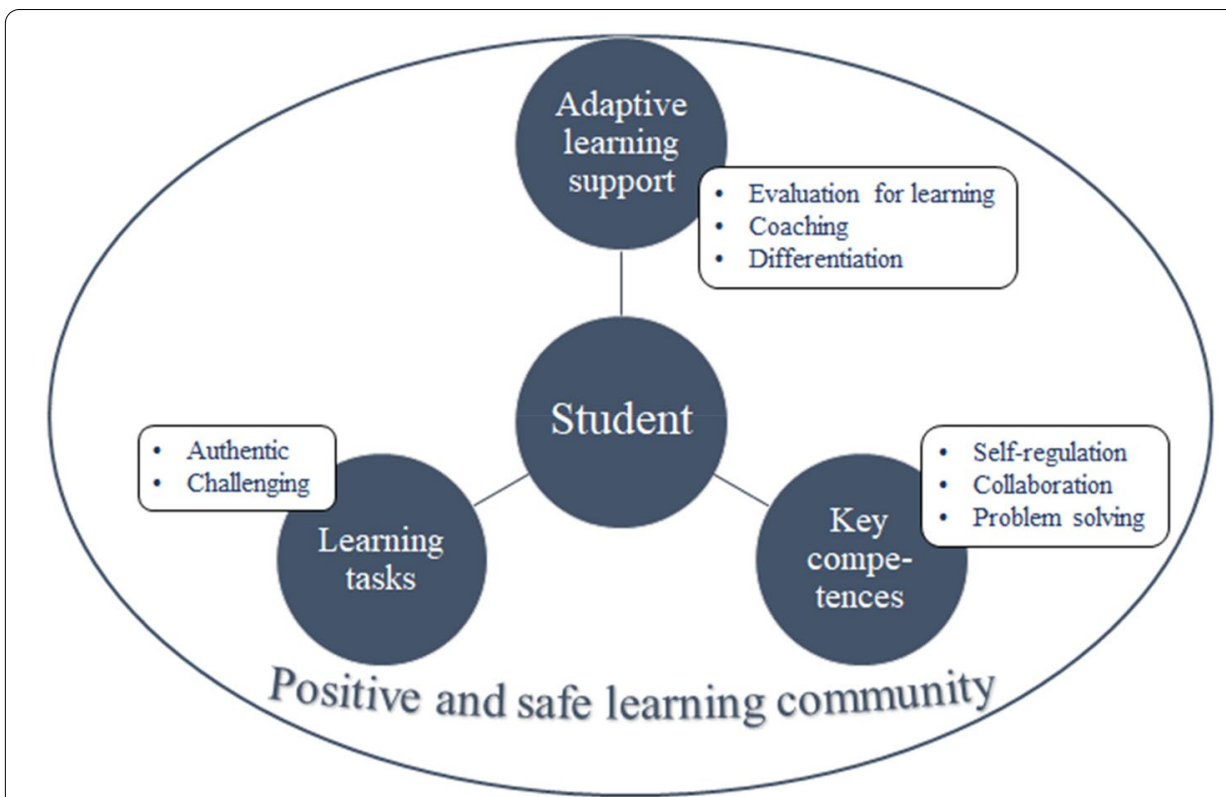

Fig. 1 Model of powerful learning environments in vocational education (adapted from Placklé et al. 2014, p. $111 ; 2018$, p. $28 ; 2020$, p. 237)

and a physical environment that imitate the real world, engaging students and using complex learning tasks are also important (Herrington et al. 2003).

Placklé et al. (2020) have found that while students preferred intellectually challenging learning tasks connected to real-life situations, the teachers, on the other hand, felt safer with realistic cases within the school environment and doubted the effectiveness of learning from real-life experiences. Investigating eleven vocational courses de Bruijn and Leeman (2011) found that authentic learning was limited in most courses, and in more authentic courses, the link between theory and practice was insufficient. However, knowing and understanding of theoretical concepts are vital for challenging tasks (de Bruijn and Leeman 2011).

An essential characteristic of the PoLEVE is providing learners with the opportunity to develop their key competencies, particularly self-regulated and cooperative learning and problem-solving skills (Placklé et al. 2014, 2018, 2020). Self-regulated learning means that learners are active in the learning process, construct meanings, and regulate and control their cognitive and motivational processes and behavior (Pintrich 2004). To achieve this, it is crucial to develop students' metacognitive regulation skills, goal setting, planning, and choice-making through supportive guidance, and reflective dialogue (Placklé et al. 2020). This is done by teaching students to control their learning process, starting with precise external regulation and support and as they acquire self-directed learning skills, progressively giving the responsibility for learning to students (Vermunt 2003).

Effective learning environments promote learners' engagement in solving real-world problems (Merrill 2002) and stimulate interaction and communication in collaborative knowledge construction (van Merriënboer and Paas 2003). However, previous findings show that while teachers consider reflection important, they are unsure how to set up reflective dialogues with students (Placklé et al. 2020), and their knowledge 
of developing students' self-regulated skills must be improved (de Bruijn and Leeman 2011; de Corte 2019). Research also shows that vocational students do not feel capable of directing their own learning (de Bruijn and Leeman 2011). They prefer action in collaborative problem-solving and find forethought, problem analysis (Placklé et al. 2020), and reflection unnecessary (Placklé et al. 2014; 2018; 2020).

Also, adaptive support for teaching and learning is a characteristic of the PoLEVE (Placklé et al. 2014, 2018, 2020). Because of learners' diversity, the curriculum should be adapted according to their individual needs (De Bruijn and Leeman 2011; Placklé et al. 2014). To optimize each student's learning process, teachers should first accept students' diversity, seek to understand their needs and interests, and adopt a mindset oriented towards positive growth and success (Tomlinson and Javius 2012). Adapting includes considering the learner's motivation (Schaap et al. 2012), learning styles (Schaap et al. 2012; Königs et al. 2005; Tomlinson and Javius 2012), needs and preferences (Placklé et al. 2014) as well as providing challenging tasks (Placklé et al. 2014, 2018; Tomlinson and Javius 2012).

Adaptive guidance and modeling, including teachers supporting students in understanding subjects and being role models for acquiring vocational competence (de Bruijn and Leeman 2011) and differentiated guidance (Santangelo and Tomlinson 2009), have been emphasized. In order to improve learning for all students, adaptive strategies and differentiation must be a part of the educational approach (Tomlinson and Javius 2012). In a powerful learning environment, teachers are available for students to coach them in their learning, helping them reflect on their learning processes and outcomes (de Bruijn and Leeman 2011).

Feedback should focus on enhancing learners' commitment and efforts (Jossberger et al. 2010) and rely on the strengths, abilities, and needs of students (Jennings and Greenberg 2009). Ideally, pre-and formative assessments are used to identify students' interests, readiness, and learning profiles for the planning and supporting learning in a differentiated manner (Tomlinson 2014), and students are engaged in the evaluation process (Placklé et al. 2020).

There is, however, evidence that while teachers find adaptive teaching and coaching important (Placklé et al. 2020), these practices may be frequent in vocational education programs (de Bruijn and Leeman 2011). Students often do not perceive differentiation as fair, although for themselves, they desire that learning tasks are adapted to their needs, interest, and abilities (Placklé et al. 2014, 2018).

A safe and positive learning community is essential for the emergence of other characteristics of PoLEVE (Placklé et al. 2014, 2018, 2020). Warm and supportive relationships between the teachers and students and among the students are vital (Jennings and Greenberg 2009). A safe and positive environment does not emerge spontaneously-teachers play a significant role in creating it (Fix et al. 2019), showing that the classroom is a safe and important place and being enthusiastic about learning (Jennings and Greenberg 2009). Such teachers believe that they can teach every student and that every student can learn (Hopkins 2000).

According to Hopkins (2000), powerful learning and teaching finds place in schools with organizational culture defined by collaboration. Close cooperation is crucial 
between teachers of practical and general vocational training subjects (de Bruijn and Leeman 2011), as between schools and within the community (Ainscow et al. 2012).

Previous findings by Placklé et al. (2020) show that both students and teachers emphasize a positive and safe atmosphere as a necessary precondition for a powerful learning environment in vocational education. In their research on vocational curricula for at-risk students, Fix et al. (2019) indicated the need for positive and equal relationships between teachers and students and care and respect for each other. They suggested cautious attention to the part of the peer group, as peers can have a positive and negative influence on students.

To conclude the overview of the PoLEVE model, it is important to be aware that the various characteristics in it are interdependent, "and in interaction with each other, aim to maximally improve learning-including engagement on the part of every student" (Placklé et al. 2018, p. 28). Furthermore, one challenging aspect is balancing the characteristics of a powerful learning environment when implementing it (de Bruijn and Leeman 2011).

\section{The context of the study}

Before we describe and discuss methodological choices of this study, we briefly explain the context of it. In Estonia, nine years of basic education are compulsory. After graduating from basic education, the alternatives for proceeding with the studies are general secondary education and vocational upper secondary education. The number of students in upper-secondary VET is decreasing, despite the government's efforts to popularize VET. Only about $25 \%$ of the compulsory basic education graduates proceed with their studies in a vocational program (Musset et al. 2019), delivered by 37 different VET providers with more than 25,000 students (Statistics Estonia n.d.). Generally, graduates with lower grade point average choose VET. Approximately $25 \%$ of those who start their studies in VET drop out in the first year of their studies. The main challenge is keeping the at-risk students in VET, as low grades in basic school, previous negative learning experiences (Ministry of Education and Research 2017), lack of study habits and interest in the specialty, and low engagement characterize typical dropouts (Beilmann and Espenberg 2016).

To overcome this challenge, a preparatory transition program to VET has been established, the choice of profession training (CoPT) aiming to support youth's readiness for continuing studies or entering the labor market (Standard of Vocational Education 2013). After piloting CoPT in two vocational schools in 2016-2018, from 2019, the Ministry of Education and Research authorized CoPT as a formal educational program. Students can enroll in CoPT without prior basic education requirement. They will obtain learning outcomes equivalent to the second qualification level according to the European Qualification Framework (EQF). The second EQF qualification level refers to acquiring basic cognitive and practical skills to carry out tasks and solve routine problems under supervision with some autonomy (European Union n.d.). However, CoPT does not lead to a formal qualification or completing compulsory basic education.

A half-year curriculum with a volume of 30 credit points aims to address the needs of those who are unsure about career choice, who have dropped out of school, or who need supplementary preparations for continuing studies. Alternatively, a 1-year 
curriculum with a volume of 60 credit points can be adapted for students with special educational needs. However, there is no national curriculum for CoPT. VET schools can plan a relatively autonomous curriculum, as long as the elective studies, including practical training in different specialties chosen by students, make up at least $70 \%$ of the training volume. The core studies with a volume of $30 \%$ are meant to develop students' key competencies and upgrade their knowledge in general subjects (Standard of Vocational Education 2013).

An essential part of the general and elective modules of an outcome-based CoPT curriculum is supporting an informed career choice by developing students' practical skills and key competencies (Kinkar et al. 2019). The students are expected to fulfill work assignments with limited responsibility in their vocational field. In addition, the following key competencies are highlighted: learning-, communicative-, self-determination, performance-, information technology-, initiative, and entrepreneurial competence (Standard of Vocational Education 2013).

In these programs teachers and support specialists work together in supporting the students to gain the aims of the program (Kinkar et al. 2019). Besides teachers for vocational subjects who develop students' practical skills and theoretical knowledge, support specialists are important members of school staff (Vocational Educational Institutions Act 2013). Schools employ special education teachers, school psychologists and social pedagogues and others for counselling and developing the social skills of students (Santiago et al. 2016).

To date, there are no studies on Estonian preparatory VET transition program experiences, and this study aims to close this gap. We rely on teachers and support specialists' experiences, as they play a central role in creating a supportive learning environment (Fix et al. 2019; Jäppinen 2012; Königs et al. 2005; Placklé et al. 2018). By applying the research-based model of PoLEVE (Placklé et al. 2014, 2018), we also aim to expand existing knowledge of transition programs. The following research question is addressed: how are the characteristics of the PoLEVE model appearing in CoPT in VET teachers' and support specialists' experiences implementing it?

\section{Methods}

\section{Respondents}

The findings of this study are based on 16 semi-structured interviews with teachers and support specialists from two Estonian vocational schools. The selection of VET schools has not been random, both schools were working with the students of the CoPT program since the piloting phase in 2016-2018. Respondents involved in this study were teachers of general and practical subjects, CoPT course instructors and support specialists (career counselors, special education teachers, social pedagogues). Several respondents fulfilled multiple roles at the same time, for example, being a teacher and a course instructor. The primary inclusion criteria for the purposive sample was experience in implementing the choice of profession training. To ensure the confidentiality of the interviewees, additional background information about the interviewees is not provided here. Participation in the study was voluntary and based on informed consent. 


\section{The procedure of the study}

For "rich and in-depth information about the experiences" (DiCicco-Bloom and Crabtree 2006, p. 319), data were collected using semi-structured interviews. The interviews were conducted in autumn and winter 2019 by the article's authors. The open questions in the semi-structured interview guide addressed teachers' and support specialists' experiences in implementing the CoPT through themes like the rationale behind the program, its content, learning activities and assessment, the teacher's role in it; forming the study groups; and the learning environment. The data were collected for a more general purpose of gathering VET teachers' and support specialists' experiences gained in piloting the CoPT. Therefore, the interview guide did not address the characteristics of the PoLEVE model directly and the respondents could describe their experiences in free form using their own words. The length of the interviews ranged from half an hour to $2 \mathrm{~h}$. The interviews were recorded and transcribed.

Theory-driven thematic analysis was used for data analysis, aiming to identify recurrent themes in the data set (Braun and Clarke 2006). The study embraced the theoretical model of powerful learning environments in vocational education (Placklé et al. 2014, 2018) as a coding template. More precisely, the list of four characteristics of the PoLEVE model (1) challenging and authentic learning tasks; (2) possibilities for the development of learners' key competencies; (3) adaptive support for learning; and (4) a positive and safe learning community was used as a basis for identifying themes within the data (Table 1).

The phases of thematic analysis (Braun and Clarke 2006) were followed in the analysis process. First, all authors repeatedly read the full transcripts of the interviews to familiarize themselves with the data. In the next step, using the PoLEVE model characteristics (Placklé et al. 2014, 2018) as a template, phrases where a whole thought was expressed corresponding to the characteristics in the template from the interviews were extracted.

Table 1 Coding template based on characteristics of the model of powerful learning environments in vocational education (Placklé et al. 2014, 2018)

\begin{tabular}{lc}
\hline $\begin{array}{l}\text { Main themes: characteristics of powerful learning } \\
\text { environments in vocational education }\end{array}$ & Descriptions of the themes \\
\hline Challenging and authentic learning tasks & $\begin{array}{c}\text { Intellectually challenging and complex learning tasks } \\
\text { connected to real-life situations in an authentic } \\
\text { context, with the emphasis on practical learning for } \\
\text { integrated acquisition of vocational skills, knowledge } \\
\text { and key competencies }\end{array}$ \\
Creating opportunities for developing self-regulated, \\
cooperative learning and problem-solving skills. \\
Promoting students'active engagement in regulat- \\
ing and controlling their learning process through \\
scaffolding and reflective dialog; stimulating interac- \\
tion and communication with peers and teachers in \\
collaborative knowledge construction \\
Supporting students'learning through adaptive \\
guidance, modelling, coaching, and differentiated \\
teaching to meet their individual needs, strengths \\
and abilities. Pre- and formative assessment for the \\
planning and supporting differentiated teaching \\
Adaptive teaching and learning support & $\begin{array}{l}\text { Warm and supportive relationships between students } \\
\text { and teachers, close cooperation between teachers }\end{array}$ \\
and other stakeholders in and outside the school
\end{tabular}


Items potentially of interest were marked and initial codes were elaborated. To ensure the credibility of the study, we used re-coding, peer-debriefing, and researcher triangulation. All authors did the initial coding of the data and carried out an additional recoding. The authors discussed the initial codes, identified differences, and discussed the codes' names until they reached a consensus.

Then, to produce a more genuine description of the data set, an inductive approach was used to organize the codes into data-driven sub-themes based on similar meanings. During peer-debriefings, the sub-themes were reviewed. The content and the names were clarified by interpreting the initial descriptive results and producing a final thematic overview of the data. At this phase, the authors interpreted the data regarding how the CoPT aligned to the theoretical framework.

The quality criteria, concept, and procedures of thematic analysis (Nowell et al. 2017) were considered throughout the process to ensure the analysis's trustworthiness. We aimed for a rich analysis of the data through the iterative analysis process, comprehensive engagement with the data, revisiting the theory, and peer-discussions among the authors.

\section{Results}

As a result of the iterative analysis process, we established eight data-driven sub-themes under four main theory-driven themes as an answer to the research question on how the characteristics of the PoLEVE model appeared in CoPT in VET teachers' and support specialists' experiences implementing it (see Table 2). From the coding template based on the theoretical model of PoLEVE (Placklé et al. 2014, 2018), two characteristics, namely adaptive teaching and learning support, and a safe and positive learning community, appeared in the data set more distinctly. Other characteristics were more silent, taking a more subtle or indirect form than described in the initial theoretical concept. The subtle forms of the characteristics are indicated in the bottom-up labels of the sub-themes.

The following pages present the summarized results organized by the theory-based themes (in bold) and describe the appearance of the PoLEVE model characteristics in CoPT through inductively labelled sub-themes (in italics). The overview includes

Table 2 The appearance of the PoLEVE model characteristics in COPT in VET teachers' and support specialists' experiences

\begin{tabular}{ll}
\hline $\begin{array}{l}\text { Theory-based main themes (Placklé et al. 2014, } \\
\text { 2018) }\end{array}$ & Data-driven sub-themes \\
\hline Challenging and authentic learning tasks & $\begin{array}{l}\text { Practical learning tasks in an authentic learning envi- } \\
\text { ronment } \\
\text { Development of learning- and life skills } \\
\text { Development of cooperative skills } \\
\text { Development of self-determination skills } \\
\text { Reflective dialogue } \\
\text { competencies }\end{array}$ \\
$\begin{array}{l}\text { Differentiated teaching and instruction } \\
\text { Emphasis on formative assessment and empowering } \\
\text { feedback }\end{array}$ \\
A safe and positive learning community & A safe and positive learning community \\
\hline
\end{tabular}


quotations from the interviews (in italics) to illustrate and substantiate the results. The quotations are presented with a unique interviewee code (e.g., I1, I2).

\section{Authentic and challenging learning tasks}

The characteristic of authentic and challenging learning tasks appeared in the form of practical learning tasks in an authentic learning environment. According to the interviewees, learning in CoPT took place mainly as practical training through learning and work tasks related to real-life situations. When choosing learning tasks in a school environment, their connection to the world of work was considered necessary. One of the interviewed teachers described authentic learning tasks as follows:

"In practical training, we give them real tasks from actual clients. Furthermore, the student has to complete such an assignment from start to finish /.../” (I2)

The quotation illustrates that teachers looked for assignments related to authentic work-life and let the students take up practical work on orders from actual clients. However, taking up such real-life tasks was relatively rare and available to students with exceptional talent, as in most cases, depending on students' abilities and knowledge, the authenticity meant observing or performing simpler tasks.

In addition to realistic learning tasks within the school environment, creating opportunities for real-life experiences outside the school was a part of implementing the CoPT program in respondents' experiences. Study visits to different enterprises with the students are undertaken, coping with everyday tasks' management is practiced, for example, through collective visits to the bank and unemployment insurance fund offices. The interviewees said that learners' real-life work experiences were linked to volunteer work in various organizations, such as youth centers, animal shelters, or elderly homes. For many learners, this was their first window into the world of work and an opportunity to challenge themselves. According to the respondents, some students discovered new aspects of themselves by volunteering, which helped them choose a specialty for further training, or they chose the same career for their future work life.

However, intellectually challenging learning tasks, and knowing and understanding the theoretical concepts underlying the practical tasks were less evident in the data. Interviewed teachers stated that for students, the emphasis in CoPT is put on familiarizing oneself and "trying on" different specialties through observing and getting their hands on more uncomplicated practical tasks. So rather than being intellectually challenging, the suitability or appealingness of tasks related to a particular specialty was more important. CoPT students seldom participated in theoretical classes. Therefore, as stated in the interviews, one hurdle in CoPT was that learners in certain study-fields only saw vocational training's most exciting side:

"Right now, there is much practical training, and everything is interesting, but in real life, you need other knowledge in your job as well. You just have to open a textbook /.../ and read some more theory. This 'boring bit' can sometimes get left out in some cases, and they're only exposed to the more exciting part, not real life." (I8) 
In the quotation above the interviewee was sharing feedback from a CoPT alumni, showing that while exploring specialties is exciting, some students miss the intellectual challenge and a more realistic understanding of a vocation. The data reveals that teaching content should include routine obligations, and learners should be familiarized with the realities of working life, including knowing safety rules and learning about vocational theory.

\section{Creating opportunities for the development of key competencies}

The characteristic of creating opportunities for developing key competencies-self-regulated learning, cooperative learning, and problem-solving-appeared in CoPT as fair features of strengthening students' learning-, life- and cooperation skills as well as selfdetermination skills in interviewees' experiences.

Initiations of self-regulated learning in terms of students being active in the learning process, constructing meanings, and regulating and controlling their cognitive and motivational processes and behavior were expressed by interviewed teachers and support specialists. However, in interviewees' experiences, learning skills and habits often had to be taught from the very beginning. At the beginning of the CoPT, students needed much external regulation and in many cases were not yet ready to take control and responsibility for their learning. Interruptions in study routines (e.g., changes in training schedule and lesson plans, holidays) harmed learners' learning habits in CoPT in teachers' and support specialists' experiences. They said that learners who struggled to stay in school could quickly drop out due to these interruptions in routines. These experiences illustrate the fragility of the developed learning and self-regulation skills of CoPT students. Nevertheless, developing learning skills was important, as one of the teachers emphasized:

"I would put communication and learning skills first ... to learn how to learn. And then the practical skills follow." (I11)

Besides learning to learn again, developing students' life skills starting with everyday routines like waking up early in the morning, coming to school, were emphasized in the interviews. For example, quite often, teachers struggled to get the students to show up in school or appointments outside the school as agreed. Experiences were described, where the teacher had to accompany or personally transport the students to their appointments. Otherwise, the students would not go for reasons described by the following interviewee:

"It is maybe strange for those who have had no contact with youngsters like this, but they are helpless in their social skills. They lack communication skills and courage, courage to go to someplace they don't know." (I5)

Therefore, although one of the formal aims in CoPT is to support students' educational choices, teachers and support specialists considered teaching life skills essential:

'The content of our curriculum is all about enhancing learners' coping skills and key competencies as well as teaching vocational skills, but the most important thing is coping with everyday tasks and developing independence for the future." (V14) 
To achieve this, teachers created opportunities for learners to reenact realistic everyday situations. Skills like time-management and independent movement between different study locations had to be practiced and, for example, the proper behavior at the cinema or theatre.

In addition, teachers and support specialists highlighted the need to develop students' self-determination skills by helping learners better understand themselves, gain courage, and cope with their emotions or fear of failure. Boosting the self-esteem and self-confidence of learners was considered necessary, as CoPT students may have had prior negative learning experiences. As illustrated by the quotation below, an important aspect for the interviewees was that learning more about oneself led students to more realistic choices in terms of choosing a suitable vocational path:

"Well /.../ I mean that's where you become aware of your genuine desires or the options you have. It's also kind of bringing them back down to earth in a sense." (I3)

Becoming more aware of oneself, one's assumptions, strengths, weaknesses, and interests were supported through reflective tasks in subjects related to career planning and learning skills. To help learners get to know themselves and track their progress, teachers of career planning and learning skills subjects used appraisals, reflective dialogue on the current situation, and adapted plans together with the student, if necessary:

"From time to time, we sit down together one-to-one to discuss how they've been doing and whether we should make any changes to their plan." (I8)

However, reflection was not expressed to be a part in practical subjects, where the aim was to interest students in a field of study by experimenting with different career options through practical training. Learners in CoPT were allowed to question their initial choice, change their minds, give something up and try something else. According to the interviewees, learners in CoPT were encouraged to make choices for themselves once they had discovered their inner resources upon completing the curriculum. The interviewees expressed it as the aim of the program. Still, according to the respondents' experiences, in some cases, students made decisions about further training based on sympathy towards some teachers in a particular field of study or based on a limited choice of vocational programs rather than being defined by a deep understanding of oneself' $s$ goals and resources gained through dialogical reflections about their learning experiences.

Similar to learning skills, CoPT students' cooperation skills had to be rebuilt from the beginning. According to the interviewees, it was challenging to practice cooperative learning and develop a sense of unity in the group because of the CoPT learners' diversity. Group work was practiced step by step, without any learners being forced to join the group.

"I can't just outright divide them into groups and start doing group work. I have to feel it out and approach it slowly. I often say to them that if you don't want to work in a pair today, do something else." (I8)

In respondents' experiences, students had to learn how to open up and trust peers and teachers again, how to cope in group situations and communicate with their 
peers and the teachers. Even though learning activities were initially mostly individual and completed with one-on-one guidance from the teachers and support specialists, learners were gradually guided to study with their peers over time.

Opportunities for students to formulate problems and seek solutions were less expressed in interviews. As problem-solving through authentic and complex assignments requires theoretical knowledge, the tasks teachers could give CoPT students had to be more modest.

"The students often lack the theoretical basis, so what they can do is observe /.../ They can see and feel the milieu of the workplace /.../, and even if they are not deeply familiar with the domain, they still can observe or do simpler tasks." (I8)

\section{Adaptive teaching and learning support}

Teachers and support specialists highlighted the importance of adaptive teaching and learning support and described how it was put into practice in differentiated teaching and instruction, and formative assessment and empowering feedback.

Interviewees expressed an understanding of CoPT students' diversity and a growth mindset. In their experiences a group could consist of learners who were unsure of their career choice, who dropped out of school, and who had learning difficulties and other special educational needs, mental disorders, or behavioral problems like addiction problems. This set a challenge for teachers and support specialists in meeting their individual needs and interests and supporting their development:

"Learners in choice of profession training who come to our school have diverse backgrounds. So, they can't be treated like some monolithic group." (I15)

It was also evident that teachers who were involved with teaching the CoPT students were carefully selected as they had to bring along a certain mindset and readiness to support diverse students. One of the teachers of a practical subject discussed as follows:

"Not all teachers are ready to contribute to the choice of profession training. They take the students into their classes, but they do not actually engage them. /... It could be because they don't really believe in those students. /.../But it is clear that the students need the support. They need that we (teachers) believe in them. The belief in students is a great thing that moves things forward." (I6)

Due to students' diversity, differentiation in teaching and instruction was implemented. For example, because CoPT students were at very different levels in general subjects, the interviewees felt that learning should be based on students' levels of knowledge. An interviewee explained this:

"Right now, we have a math's course that starts with third-grade stuff and ends at the tenth-grade level. Even though everyone's already graduated from the ninth grade." (I1)

Students were allowed to study at their own pace without fear of getting poor grades. To support students at different learning levels, interviewees used learning materials 
adapted to the students' individual needs, such as individual worksheets, tasks with varying degrees of difficulty, and other learning materials.

The respondents described instruction adapted to students' individual needs and characteristics. As learners' skills developed, the amount of support was gradually reduced. The interviewees believed that their role was to support, advise, motivate, and acknowledge learners' efforts while guiding them through practical activities towards career choices most suitable for them. In their experiences, most CoPT students required comprehensive explanations and repetition at the beginning of the learning process. In addition, visualization and demonstrations by teachers were used. The interviewees pointed out that in addition to them being role models for acquiring vocational skills, CoPT students also learn by observing their more advanced fellow students enrolled in vocational studies in other study groups when CoPT students join them in practical training:

"We don't make their lives too comfortable in that sense. We put them in a situation where they have to join an unfamiliar group for their practical training. And they don't even realize what a big step that is until they've taken it." (I1)

When joining other study groups in practical training, the CoPT students are allowed to observe others and when ready to join them in fulfilling simpler tasks. In addition, providing students with the option of learning in private and separately from others if they need it was outlined.

Another recurrent theme in interviews was tracking and supporting learners' development with formative assessments and empowering feedback. According to the interviewees, undifferentiated assessment was essential for creating learning experiences that enabled students to overcome negative learning experiences from the past. During the admissions interview, students' expectations were discussed to establish a learning pathway according to the learner's abilities and interests. In interviewees' experiences, empowering feedback was given at the end of an activity to support students' self-confidence and learning motivation and create daily study routines.

"There always needs to be some compliment in there that motivates them because once they start assimilating into society and go to work, it's important that that's noticed and that the little things they're doing well are acknowledged. Those little things have to be developed." (I11)

The interviewees emphasized that rather than assess numerically every small task that learners complete, it was much more critical for teachers that the students learned something about themselves. Depending on the abilities of the learners, some teachers included students in the assessment process. For example, discussions about learning at the end of classes or self-assessments were described in some cases. However, not all interviewees brought up initiating reflective dialogue about students' learning process and outcomes.

\section{A safe and positive learning community}

The characteristic of a safe and positive learning community clearly appeared in interviewees experiences on implementing CoPT. The interviewed teachers and support specialists stated that establishing a trust relationship with learners was the first important 
step, as CoPT students could have had behavioral problems or had prior negative experiences with teachers and learning.

"The most challenging part is making that initial connection with a student even to start to trust us... That aside, teaching a specialty is actually easy. /.../ But the most important thing is to make that connection, to build trust." (I2)

The interviews revealed that a particularly significant aspect for the given target group was a positive and safe social and physical learning environment. Although CoPT students participated in courses and practical training across the school building and activities outside the school, a so-called stable home-classroom where they could come back to any time and feel safe was considered crucial for the students in interviewees' experiences.

In addition, a need for a safe socio-emotional environment was emphasized by the interviewees. Appropriate, respectful, and accepting communication alongside properly expressed emotions in interactions between peers created and maintained an optimal climate. However, considering students' diverse needs and backgrounds was important for creating a safe socio-emotional environment. Here, the critical issue was how to form CoPT study groups. In addition to the group members' compatibility, the, sometimes harmful, effect that the learners may have on one another had to be considered according to the interviewees.

A safe, inclusive and learner-friendly school climate was also essential in interviewees' opinions. They wanted learners to feel comfortable and considered it necessary that teachers and students from other study groups have a positive attitude towards the students in the CoPT group. In addition to the formal learning environment, the interviewees also valued safe and learner-friendly networking with stakeholders outside the school. In their experiences, a supportive learning environment in CoPT functioned as a cooperation network that, in addition to schools' support system (e.g., special education teachers, psychologists, social pedagogues, and career counselors), included participants outside the school, such as the local government and other service providers (unemployment insurance fund, etc.).

However, the interviewees also admitted that a physically and socially protected environment could be restricting:

"They should be included more in meeting their everyday needs /.../ meaning that an overprotective and secure environment is - well, they should take more responsibility for themselves." (I15)

The quotation illustrates that while a supportive and safe environment is crucial for supporting the CoPT students' learning and weighed career choices, a balance has to be found as the broader aim of the program is to increase learners' social contacts and support their ability to cope in different environments.

\section{Discussion}

This study shows that in VET teachers' and support specialists' experiences, the characteristics of a powerful learning environment in vocational education are apparent in the vocational transition program CoPT with some limitations that are explicable with 
the program's aim of supporting informed career choices and the diverse group of atrisk students the program is targeting. In the final sections we interpret and discuss the main findings in the light of the characteristics of the PoLEVE model and of previous research, followed by outlining the implications and discussing the limitations of the current study.

According to the theoretical framework, the main key competencies which are developed in a powerful learning environment are self-regulated and cooperative learning and problem-solving skills (Placklé et al. 2014, 2018, 2020). Previous studies showed that the development of key competencies was seen as one measure supporting career counseling efficiency and preventing students from dropping out of vocational school (Frey et al. 2014). Taking into account the diversity of the programs' target group, e.g., dropouts, students with special educational needs, mental disorders, behavioral problems, the findings revealed that for CoPT, primary skills like learning to learn, developing life skills, cooperation skills and self-determination skills were relevant. As students were not ready to take responsibility for their learning, external regulation was necessary, and learning and life skills had to be taught. In addition, the results showed that interruptions in programs' routines were critical for CoPT students' disengagement. According to respondents' experiences, students' different backgrounds, levels of knowledge, learning difficulties, and behavioral problems often limited the use of cooperative learning. The results in the form of the fragility of these skills have to be considered when planning activities and time-frames in transition programs for at-risk students. The implications are supported by previous research, where supporting students in maintaining a regular daily rhythm was considered one of the most critical transitional challenges (Jäppinen 2012), and students' diverse individual and social characteristics were observed to influence teaching practices and group-management processes (Peinemann 2019).

The PoLEVE model emphasizes reflection and reflective dialogue with peers and teachers for an effective learning process (Placklé et al. 2014, 2018, 2020). Our findings indicate that in CoPT, reflective dialogue is initiated in subjects related to career planning and learning skills to develop students' self-determination skills, helping them overcome negative past learning experiences and expectedly leading to a more realistic career choice. However, in practical training, the hands-on approach was the leading practice rather than dialogues about learning processes and outcomes. The findings are consistent with those of Placklé et al. (2020) and de Bruijn and Leemann (2011), who have pointed out that reflection as a crucial element of the model is merely a part of teaching practice. Therefore, similarly to some other authors (e.g., de Bruijn and Leemann 2011; Winters et al. 2013), we emphasize the need for a more dialogical approach to reflection through teaching and learning.

According to the theoretical model, the development of key competencies is possible with adaptive support for learning (Placklé et al. 2014, 2018, 2020). This is based on the teachers' readiness and ability to notice and acknowledge students' diversity and growthand success-oriented mindset (Tomlinson and Javius 2012) and differentiation of teaching (Placklé et al. 2020). The results of this study indicate that in CoPT, the characteristic of adaptive teaching and learning support was clearly evident. In line with the theoretical model, this included identifying learners' prior knowledge, considering their level of knowledge (cf Placklé et al. 2020; Schaap et al. 2012), and using formative assessment 
(cf Tomlinson 2014) as well as self-assessment based on the learners' abilities (cf Placklé et al. 2014). Consistent with the literature (Tomlinson and Javius 2012), this research found that teachers and support specialists implementing CoPT accepted students' diversity, had a growth mindset, and were ready to support diverse students. Differentiated teaching and instruction, teacher- and peer modeling were practiced, empowering feedback was given, and the amount of support was gradually reduced. These results further support the idea that curricula should be adapted according to students' diverse individual needs to optimize each student's learning (de Bruijn and Leemann 2011; Placklé et al. 2014).

Previous research has found that besides adaptively supporting students' learning in a powerful learning environment, it is also important to provide authentic learning tasks, which challenge students intellectually (Placklé et al. 2014, 2018; Tomlinson and Javius 2012). Our results highlighted practical learning tasks in authentic learning environments in CoPT. Indeed, the main focus in CoPT is on practical learning (Kinkar et al. 2019). However, thus far, de Bruijn and Leeman (2011) have revealed that authenticity can be a quite limited characteristic in vocational courses, being dependent on teachers' commitment and devotion. Based on the findings of the current study, for most of the CoPT students, authentic tasks were confined to observation and more uncomplicated tasks in practical training in a school environment imitating the work-environment. For example, study-visits to different enterprises or creating opportunities for volunteer work opened doors to an authentic world of work. The way of how authenticity appeared in CoPT is explainable with the program's aim, indicating creating opportunities for students to familiarize themselves and experiment with different specialties.

Although Placklé et al. (2014) state that authentic and practical tasks carried out in realistic or real-life situations are both meaningful and challenging for learners, there is also evidence that besides practical performance, knowing and understanding of theoretical concepts are vital for challenging tasks (de Bruijn and Leeman 2011). Compared with the characteristics of the theoretical model, the intellectually challenging aspect was less evident in CoPT. As participation in theoretical subjects was not accentuated in the program, giving students complex and challenging assignments was a rather unlikely practice. Furthermore, the results indicate that learners could be given a more realistic understanding of a vocation by providing more detail on its theoretical background. Therefore, the intellectually challenging aspect must not be underestimated when implementing a transition program.

To date, several studies have suggested that due to the target group's vulnerability, schools must develop a positive learning environment and culture, giving a 'second chance' to transitional learners (Botha and Kourkoutas 2016; Jäppinen 2012). In a similar vein, the current findings on CoPT demonstrated a safe and positive learning community. The interviewees emphasized the need for creating positive relationships with the students, and a multi-level and multi-professional cooperation with stakeholders in- and outside the school to support students' development. These findings are supported by previous research where the vital role of communication between teachers (de Bruijn and Leeman 2011) and in the context of a wider cooperative community of vocational schools (Ainscow et al. 2012) were indicated. Although a safe and positive learning community is a prerequisite for the emergence of other characteristics of powerful learning 
environments according to the model of PoLEVE (Placklé et al. 2014, 2018, 2020), our results reflected on the boundaries from where the protected environment could begin to restrict students' ability for independent networking outside the safe and well-known environment, well needed in further studies or work-life. In addition, supported by observations in some earlier studies (e.g., Fix et al. 2019), the findings of this study suggest cautious group formation for programs designed for at-risk students due to the potential negative influence of peers.

The paper presented the first investigation of a transition program for at-risk students in Estonia. While contributing to existing knowledge of transition programs through utilizing the research-based model of powerful learning environments in vocational education by Placklé et al. $(2014,2018)$, the study has some limitations. First, the characteristics of powerful learning environments in CoPT were identified based on the authors' interpretations as the interviewees were not asked directly about the appearance of characteristics of PoLEVE in CoPT. Therefore, the fact that the findings do not reflect all the characteristics fully does not necessarily indicate their definite deficiency. Had we asked the participants directly about the characteristics of PoLEVE, different results may have emerged. However, this allowed us to identify characteristics of powerful learning environments in CoPT varying from silent to more prevailing. Second, as Braun and Clark (2006) have stated, theoretical thematic analysis tends to provide a less detailed description of the data overall, concentrating on some aspects. Therefore, it is important to be aware that the results do not provide a thorough description of implementing CoPT.

\section{Conclusion}

This study has identified how the characteristics of a powerful learning environment appear in a vocational transition program for at-risk students in their teachers' and support specialists' experiences. The findings of this study implicate that with some moderation, the aspects of the theoretical model of PoLEVE are reflected in the educational practices of CoPT teachers and support specialists. While the characteristics of adaptive teaching and learning support in a safe and positive learning community appeared fully, some aspects of other characteristics were limited, for example, the investigated study programs could offer more intellectually challenging tasks. There is evidence that students themselves are asking for challenging learning pathways in vocational education (Placklé et al. 2020). Therefore, more complex and challenging assignments with some underlying theoretical knowledge could also motivate students in transition programs. When regarding the characteristics of creating opportunities for the development of key competencies, the diverse needs of the programs' target group have to be considered. Based on the findings, learning to learn, developing life skills, cooperation skills, and self-determination skills were relevant in the context of the transition program. De Bruijn and Leemann (2011) have stated that the challenging aspect in implementing a powerful learning environment is balancing the different characteristics. The learning environment of the transition program studied here could also benefit from more balanced characteristics. While creating positive learning experiences in a safe and positive learning environment is essential for at-risk students, empowering them to cope 
independently, supporting their construction of vocational knowledge through reflective dialogue and problem-solving in practical subjects could benefit them likewise.

To be able to conclude whether the PoLEVE model could be considered as a concept or which modifications are needed for transition programs, further studies are needed. Considering that the perceptions of teachers about powerful learning environments may differ from what is done in practice and from the perceptions of the learners (e.g., de Bruijn and Leeman 2011; Placklé et al. 2020), we suggest longitudinal studies of transition programs from students' perspective.

Although we cannot claim the generalizability of the findings, we still hope this paper to offer some practical implications for those designing curricula or working in the professional network of transition programs, embracing the evident characteristics of a powerful learning environment as well as targeting the potential road-bumps in it pinpointed by the current study.

\section{Acknowledgements}

Not applicable.

\section{Authors' contributions}

$\mathrm{LR}, \mathrm{KT}, \mathrm{KK}$, and ES planned and carried out the entire research process in collaboration, including the preparation of the theoretical overview of the article and the design and implementation of the empirical research. All authors conducted and transcribed the interviews, read and analyzed the transcripts, and, as a result of joint discussions and preliminary summaries, a final analysis was made and written down, with all authors' equal participation. All authors read and approved the final manuscript.

\section{Funding}

Not applicable.

\section{Availability of data and materials}

The datasets generated and analyzed during the current study are not publicly available because they contain data that allows identification of the participants. A limited form of the data can be made available from the corresponding author on reasonable request.

\section{Declarations}

Competing interests

The authors declare that they have no competing interests.

Received: 17 March 2021 Accepted: 6 August 2021

Published online: 13 August 2021

\section{References}

Ahola S, Kivelä S (2007) Education is Important, but ... Young People outside of Schooling and the Finnish Policy of Education guarantee. Educ Res 49(3):243-258. https://doi.org/10.1080/00131880701550441

Ainscow M, Dyson A, Goldrick S, West M (2012) Making schools effective for all: rethinking the task. Sch Leadersh Manag 32(3):197-213. https://doi.org/10.1080/13632434.2012.669648

Beilmann M, Espenberg K (2016) The reasons for the interruption of vocational training in Estonian vocational schools. J Vocat Educ Train 68(1):87-101. https://doi.org/10.1080/13636820.2015.1117520

Biemans HJA, de Bruijn E, den Boer PR, Teurlings CJ (2013) Differences in Design format and powerful learning environment characteristics of continuing pathways in vocational education as related to student performance and satisfaction. J Vocat Educ Train 65(1):108-126. https://doi.org/10.1080/13636820.2012.755211

Botha J, Kourkoutas E (2016) A community of practice as an inclusive model to support children with social, emotional and behavioural difficulties in school contexts. Int J Incl Educ 20(7):784-799. https://doi.org/10.1080/13603116. 2015.1111448

Braun V, Clarke V (2006) Using thematic analysis in psychology. Qual Res Psychol 3(2):77-101. https://doi.org/10.1191/ $1478088706 q \mathrm{p} 063 \mathrm{oa}$

De Bruijn E, Leeman Y (2011) Authentic and self-directed learning in vocational education: challenges to vocational educators. Teach Teach Educ 27:694-702. https://doi.org/10.1016/.tate.2010.11.007

De Corte E (2019) Learning design: creating powerful learning environments for self-regulation skills. Educ Stud Moscow 4:30-46. https://doi.org/10.17323/1814-9545-2019-4-30-46

DiCicco-Bloom B, Crabtree BF (2006) The qualitative research interview. Med Educ 40(4):314-321. https://doi.org/10. $1111 / j .1365-2929.2006 .02418 . x$ 
Espenberg K et al. (2012) Õpingute katkestamise põhjused kutseõppes (Reasons for discontinuing attendance of vocational education), University of Tartu Applied Social Sciences Research Centre (RAKE) and CPD OÜ, Tartu. https:// www.hm.ee/sites/default/files/opingute_katkestamise_pohjused_kutseoppes.pdf. Accessed 7 July 2021

European Union (n.d.) Description of the eight EQF levels. https://europa.eu/europass/en/description-eight-eqf-levels. Accessed 7 July 2021

Eurostat (2020) Eurostat regional yearbook. https://ec.europa.eu/eurostat/statistics-explained/index.php?title=Eurostat_ regional_yearbook. Accessed 6 July 2021

Fix GM, Ritzen HTM, Pieters JM, Kuiper WAJM (2019) Effective curricula for at-risk students in vocational education: a study of teachers' practice. Empir Res Vocat Educ Train 11(1):1-17. https://doi.org/10.1186/s40461-018-0076-5

Frey A, Balzer L, Ruppert JJ (2014) Transferable competences of young people with a high dropout risk in vocational training in Germany. Int J for Educ and Vocat Guid 14(1):119-134. https://doi.org/10.1007/s10775-013-9257-8

González-Faraco JC, Luzón-Trujillo A, Corchuelo-Fernández C (2019) Initial vocational education and training in a second chance school in Andalusia (Spain): a case study. The Aust Educ Res 46(5):827-842. https://doi.org/10.1007/ s13384-019-00304-8

Herrington J, Oliver R, Reeves T (2003) Cognitive realism' in online authentic learning environments. In: Lassner D, McNaught C (eds) Proceedings of world conference on educational multimedia, hypermedia and telecommunications 2003. VA: AACE, Chesapeake

Hopkins D (2000) Powerful learning, powerful teaching and powerful schools. J Educ Change 1(2):135-154. https://doi. org/10.1023/A:1010077007233

Jäppinen AK (2012) Transitions in individual vocational education pathways: challenges and collaborative solutions. In: Tynjälä P, Stenström ML, Saarnivaara M (eds) Transitions and transformations in learning and education. Springer, Dordrect, pp 103-116

Jennings PA, Greenberg MT (2009) The prosocial classroom: teacher social and emotional competence in relation to student and classroom outcomes. Rev of Educ Res 79(1):491-525. https://doi.org/10.3102/0034654308325693

Jørgensen CH (2015) Some boys' problems in education-what is the role of VET? J Vocat Educ Train 67(1):62-77. https:// doi.org/10.1080/13636820.2014.917694

Jossberger H, Brand-Gruwel S, Boshuizen H, Van de Wiel M (2010) The challenge of self-directed and self-regulated learning in vocational education: a theoretical analysis and synthesis of requirements. J Vocat Educ Train 62(4):415-440. https://doi.org/10.1080/13636820.2010.523479

Kalalahti M, Niemi AM, Varjo J, Jahnukainen M (2020) Diversified transitions and educational equality?: negotiating the transitions of young people with immigrant backgrounds and/or special educational needs. Nord Stud in Educ 40(1):36-54. https://doi.org/10.23865/nse.v40.2127

Kallip K, Heidmets M (2017) Varakult haridussüsteemist lahkumine: trendid, mõjurid ja meetmed Eestis. Est J Educ 5(2):155-182. https://doi.org/10.12697/eha.2017.5.2.07

Kinkar V, Piiskop K, Nõmmiste Ü (2019) Kutsevaliku õpe: kellele, miks, kuidas? (Choice of profession training: to whom, why, how?). SA Innove, Tallinn

Könings KD, Brand-Gruwel S, van Merriënboer JJ (2005) Towards more powerful learning environments through combining the perspectives of designers, teachers, and students. Br J Educ Psychol 75:645-660. https://doi.org/10.1348/ $000709905 \times 43616$

Merrill MD (2002) First principles of instruction. Educ Technol Res Dev 50(3):43-59. https://doi.org/10.1007/BF02505024

Ministry of Education and Research (2017) Background report for OECD on vocational education and training (VET) in Estonia. https://www.hm.ee/sites/default/files/uuringud/oecd_vet_background.pdf. Accessed 1 Mar 2021

Munns G, McFadden M (2000) First chance, second chance or last chance? Resistance and response to education. Br J of Sociol Educ 21(1):59-75. https://doi.org/10.1080/01425690095162

Musset P, Field S, Mann A, Bergseng B (2019) Vocational education and training in Estonia. OECD Reviews of Vocational Education and Training. OECD Publishing, Paris, Paris. https://doi.org/10.1787/g2g9fac9-en

Niittylahti S, Annala J, Mäkinen M (2019) Student engagement at the beginning of vocational studies. Nord J Vocat Educ and Train 9(1):21-42. https://doi.org/10.3384/njvet.2242-458X.199121

Nowell LS, Norris JM, White DE, Moules NJ (2017) Thematic analysis: striving to meet the trustworthiness criteria. Int J Qual Methods 16(1):1-13. https://doi.org/10.1177/1609406917733847

Peinemann K (2019) Orientierung im Kontext von Beruf und Arbeitswelt: allgemeine und Berufsbildende Inhalte vorberuflicher Bildungsgänge an beruflichen Schulen in Mecklenburg-Vorpommern. In: Gramlinger F, Iller C, Ostendorf A, Schmid K, Tafner G (Hrsg.), Bildung = Berufsbildung?! Beiträge zur 6. Berufsbildungsforschungskonferenz (BBFK). WBV Media GmbH \& Co. KG, Bielefeld, pp 117-131. https://doi.org/10.3278/6004660w117

Pintrich PR (2004) A conceptual framework for assessing motivation and self-regulated learning in college students. Educ Psych Rev 16(4):385-407. https://doi.org/10.1007/s10648-004-0006-x

Placklé I, Könings KD, Jacquet W, Struyven K, Libotton A, van Merriënboer JJ, Engels N (2014) Students' preferred characteristics of learning environments in vocational secondary education. Int J Res Vocat Educ Train 1(2):107-124. https://doi.org/10.13152/IJRVET.1.2.2

Placklé I, Könings KD, Jacquet W, Libotton A, van Merriënboer JJ, Engels N (2018) Students embracing change towards more powerful learning environments in vocational education. Educ Stud 44(1):26-44. https://doi.org/10.1080/ 03055698.2017 .1331840

Placklé I, Könings KD, Struyven K, Libotton A, van Merriënboer JJ, Engels N (2020) Powerful learning environments in secondary vocational education: towards a shared understanding. Eur J Teach Educ 43(2):224-242. https://doi.org/ 10.1080/02619768.2019.1681965

Santangelo T, Tomlinson CA (2009) The application of differentiated instruction in postsecondary environments: Benefits, challenges, and future directions. Int J Teach Learn High Educ 20(3):307-323. https://doi.org/10.5430/ijhe.v2n3p28

Santiago P, Levitas A, Radó P, Shewbridge C (2016) OECD reviews of school resources: Estonia 2016, OECD reviews of school resources. OECD Publishing, Paris. https://doi.org/10.1787/9789264251731-en

Schaap H, Baartman L, De Bruijn E (2012) Students' learning processes during school-based learning and workplace learning in vocational education: a review. Vocat and Learn 5(2):99-117. https://doi.org/10.1007/s12186-011-9069-2 
Schmid E (2020) Upper secondary education for youth at risk: a comparative analysis of education and training programmes in Austria, Norway, Sweden and Switzerland. Int J Res Vocat Educ Train (IJRVET) 7(1):21-44. https://doi.org/ 10.13152/IJRVET.7.1.2

Standard of Vocational Education (2013) https://www.riigiteataja.ee/en/eli/515012020003/consolide. Accessed 9 Mar 2021

Statistics Estonia (n.d.) Vocational Education. https://www.stat.ee/en/find-statistics/statistics-theme/education/vocat ional-education. Accessed 6 July 2021

Tomlinson CA (2014) The differentiated classroom: Responding to the needs of all learners. ASCD, Alexandria, Alexandria Tomlinson CA, Javius EL (2012) Teach up for excellence. Ed Leadersh 69(5):28-33

Van Merriënboer JJG, Paas F (2003) Powerful learning and the many faces of instructional design: toward a framework for the design of powerful learning environments. In: de Corte E, Verschaffel L, Entwistle N, Van Merriënboer JJG (eds) Powerful learning environments: unravelling basic components and dimensions. Pergamon, Elsevier, Oxford Vermunt J (2003) The power of learning environments and the quality of student learning. In: de Corte E, Verschaffel L, Entwistle N, Van Merriënboer JJG (eds) Powerful learning environments: unravelling basic components and dimensions. Pergamon, Elsivier, Oxford

Vocational Educational Institutions Act (2013) https://www.riigiteataja.ee/en/eli/517072020005/consolide. Accessed 30 June 2021

Walther A (2006) Regimes of youth transitions: choice, flexibility and security in young people's experiences across different European contexts. Young 14(2):119-139. https://doi.org/10.1177/1103308806062737

Winters A, Meijers F, Harlaar M, Strik A, Baert H, Kuijpers M (2013) The narrative quality of career conversations in vocational education. J Constr Psychol 26(2):115-126. https://doi.org/10.1080/10720537.2013.759026

\section{Publisher's Note}

Springer Nature remains neutral with regard to jurisdictional claims in published maps and institutional affiliations.

\section{Submit your manuscript to a SpringerOpen ${ }^{\circ}$ journal and benefit from:}

- Convenient online submission

Rigorous peer review

Open access: articles freely available online

- High visibility within the field

Retaining the copyright to your article

Submit your next manuscript at $\gg$ springeropen.com 